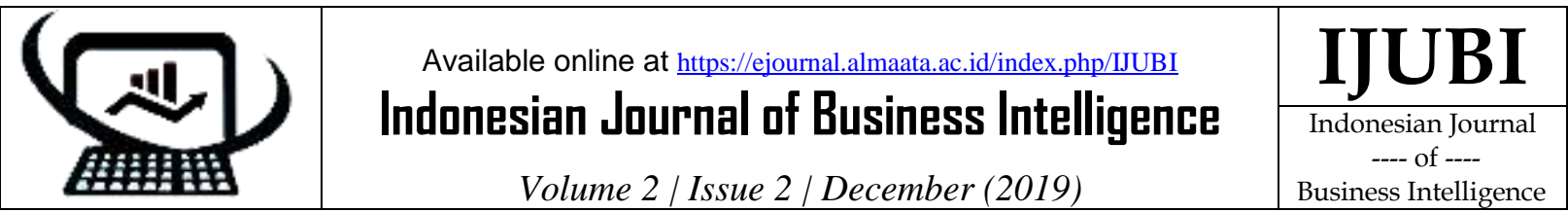

\section{PENGEMBANGAN MEDIA PEMBELAJARAN BERBASIS ANDROID PADA MATA PELAJARAN BIOLOGI KELAS XI}

Joko Kuswanto

Program Studi Informatika, Fakultas Teknik dan Komputer, Universitas Baturaja jokokuswanto@unbara.ac.id

Jl. Ki Ratu Penghulu No 02301 Karang Sari Telepon (0735) 326122 Fax. 321822

Baturaja - 32113 OKU Sumatera Selatan

Keywords:

Android, Learning, Media, Development, Biology.
Kata Kunci

Android, Media

Pembelajaran,

Pengembangan, Biologi.

\section{Abstract}

This study aims to develop android-based learning media on the subjects of biologi class XI. The research method used is research development with stages of designing, production, evaluation, and analyzing data by percentage. Based on different stages the trial was being done to experts: media experts $(78,30)$, the design (78), and the matter (80). So the percentage of overall value on the validation experts have eligibility criteria good. To scale individuals (80), small group $(80,05)$ and field test $(80,5)$. So the total value of the average percentage on of respondents with criteria good.

Abstrak
Penelitian ini bertujuan untuk mengembangkan media pembelajaran berbasis
android pada mata pelajaran biologi kelas XI. Metode penelitian yang
digunakan adalah penelitian pengembangan dengan tahapan perancangan,
produksi, evaluasi, dan menganalisis data dengan persentase. Berdasarkan
beberapa tahapan uji coba yang dilakukan kepada para ahli: ahli media $(78,30)$,
ahli desain (78), dan ahli materi (80). Jadi keseluruhan nilai rata-rata persentase
pada validasi ahli memperoleh kriteria kelayakan Baik. Untuk skala
perorangan (80, uji coba skala kecil (80,05), dan uji coba skala lapangan $(80,5)$.
Jadi secara keseluruhan nilai rata-rata persentase pada responden memperoleh
kriteria kelayakan Baik Sekali.

dan komunikasi seiring dengan perkembangan zaman. Guru yang kreatif adalah guru yang mampu memanfaatkan objek apa saja dan mengembangkan kemampuan di bidang teknologi yang terbaru sehingga mewujudkan proses belajar mengajar yang menarik [2]. Berkembangnya teknologi informasi dan komunikasi saat ini, menjadikan proses pembelajaran dapat dilakukan dimana saja dan kapan saja misalnya pembelajaran berbasis android.

Dengan adanya media pembelajaran dapat membangkitkan motivasi belajar siswa serta memungkinkan siswa dapat belajar mandiri sesuai dengan kemampuan dimanapun dan kapanpun [3]. Akan tetapi pemanfaatan dari kemajuan teknologi tersebut belum terlihat dalam pembelajaran. Berdasarkan fenomena yang terjadi saat pembelajaran di dalam kelas
Pada proses pembelajaran tersebut dibutuhkan seorang guru yang kreatif dan mampu mengintegrasikan seperti teknologi informasi 
adalah proses pembelajaran yang dilakukan guru hanya menggunakan media presentasi berupa power point yang berisikan teks saja tanpa adanya gambar dan video. Selain itu, guru dan siswa sudah memiliki handphone berbasis android namun belum dimanfaatkan untuk menunjang proses pembelajaran. Sebagian besar guru dan siswa hanya menggunakan android untuk membuka jejaring sosial atau game. Semestinya kemajuan teknologi seperti android ini bisa dimanfaatkan dalam proses pembelajaran.

Berdasarkan paparan di atas perlu adanya media pembelajaran berbasis android pada mata pelajaran biologi kelas XI. Media pembelajaran tersebut dapat dijadikan media belajar bagi peserta didik baik disekolah maupun diluar sekolah, serta dapat digunakan oleh pendidik sebagai media pembelajaran dalam proses belajar mengajar. Selain itu dengan aplikasi ini siswa diarahkan agar lebih memanfaatkan smartphone yang mereka miliki tidak hanya untuk berkomunikasi namun juga untuk ranah pendidikan.

\section{Landasan Teori}

\section{Kajian Hasil Penelitian}

Penelitian yang dilakukan oleh Moch Misbahul Arifin Afif membahas tentang pengembangan media pembelajaran berbasis android pada mata pelajaran instalasi tenaga listrik untuk meningkatkan hasil belajar siswa. Hasil penelitian menunjukkan bahwa: (1) Hasil validasi media pembelajaran dari 2 dosen dan 1 guru mata pelajaran mendapatkan nilai validasi sebesar 83,93\% dengan kriteria sangat baik atau layak, (2) respon peserta didik tentang pengembangan media pembelajaran berbasis android memperoleh rata-rata hasil rating sebesar 83,065\% dikategorikan sangat baik, (3) hasil belajar ranah kognitif didapatkan hasil - thitung<-ttabel $(-18,81<-1,699)$. Nilai hasil belajar ranah efektif sebesar 80,00. (4) uji peningkatan (gain) dapat diketahui bahwa kriteria gain tinggi $41,93 \%$, sedang 58,07\%, dan rendah $0 \%$.

Penelitian yang dilakukan oleh Kuswanto dan Radiansah yang membahasa tentang Media Pembelajaran Berbasis Android Pada Mata Pelajaran Sistem Operasi Jaringan Kelas XI. Metode penelitian yang digunakan adalah penelitian pengembangan dengan tahapan

66 "Joko Kuswanto" perancangan, produksi, evaluasi, dan menganalisis data dengan persentase. Hasil penelitian ini menunjukkan bahwa media pembelajaran berbasis android yang dikembangkan pada mata pelajaran Sistem Operasi Jaringan kelas XI sudah layak untuk digunakan dalam pembelajaran oleh guru dan siswa. Berdasarkan beberapa tahapan uji coba, media pembelajaran dikategorikan valid dengan tingkat kelayakan sebesar $82 \%$ dengan kriteria baik.

\section{Media Pembelajaran}

Bedia pembelajaran adalah alat, metodik dan teknik yang digunakan sebagai perantara komunikasi antara seorang guru dan murid dalam rangka lebih mengefektifkan komunikasi dan interaksi antara guru dan siswa dalam proses pendidikan pengajaran di sekolah [4].

\section{Manfaat Media Pembelajaran}

Manfaat media pembelajaran adalah sebagai berikut [5]:

1. Memperjelas penyajian pesan agar tidak terlalu verbalistis (tahu kata-katanya, tetapi tidak tahu maksudnya).

2. Mengatasi keterbatasan ruang, waktu daya indra.

3. Dengan menggunakan media pembelajaran yang tepat dan bervariasi dapat mengatasi sikap pasif siswa.

4. Dapat menimbulkan persepsi yang sama terhadap suatu masalah.

\section{Android}

Smartphone atau yang sering disebut dengan android adalah sebuah sistem operasi untuk smartphone dan tablet. Sistem operasi dapat diilustrasikan sebagai jembatan antara peranti (device) dan penggunaannya, sehingga pengguna dapat berinteraksi dengan device-nya dan menjalankan aplikasi-aplikasi yang tersedia pada device [6]. Android merupakan generasi baru platform mobile berbasis linux yang mencakup sistem operasi, middleware, dan aplikasi [7].

\section{Metode Penelitian}

Metodologi yang digunakan dalam penelitian ini adalah penelitian pengembangan. Merupakan penelitian yang berorientasi untuk 
mengembangkan dan memvalidasi produkproduk yang digunakan dalam pendidikan [8]. Pengembangan media pembelajaran berbasis android ini menggunakan model prosedural yaitu model yang bersifat deskriptif, menunjukkan langkah-langkah yang harus diikuti untuk menghasilkan produk [9]. Langkah-langkah prosedur pengembangan meliputi: tahap perancangan, produksi, dan evaluasi [10].

Subjek dalam penelitian ini yaitu pada tahap awal dilakukan validasi oleh expert (ahli desain, media, dan materi). Kemudian dilanjutkan uji coba produk skala perorangan, uji coba kelompok kecil dan uji lapangan. Teknik pengumpulan data dalam penelitian ini menggunakan angket. Angket digunakan untuk memperoleh informasi serta data untuk mengukur kelayakan produk yang dihasilkan.

\section{Hasil dan Pembahasan}

\section{Hasil Penelitian}

Sesuai dengan langkah - langkah pengembangan yang telah dipilih, dihasilkan rancangan, produksi dan evaluasi sebagai berikut:

a. Tahap rancangan: didapatkan hasil analisis kebutuhan berupa materi dan silabus mata pelajaran sesuai dengan kurikulum. Dilanjutkan dengan penyusunan naskah (storyboard).

b. Tahap produksi: media yang dikembangkan berupa media audiovisual yaitu penggabungan antara teks, suara, gambar dan animasi.

c. Tahap evaluasi: evaluasi pramaster yang terdiri dari evaluasi ahli, perorangan, dan kelompok kecil. Dilanjutkan dengan uji coba lapangan.

Hasil Hasil akhir dalam penelitian ini yaitu media pembelajaran berbasis android yang digunakan sebagai media pembelajaran. Aplikasi terdiri dari halaman-halaman yang saling terhubung, adapun tampilannya adalah sebagai berikut:

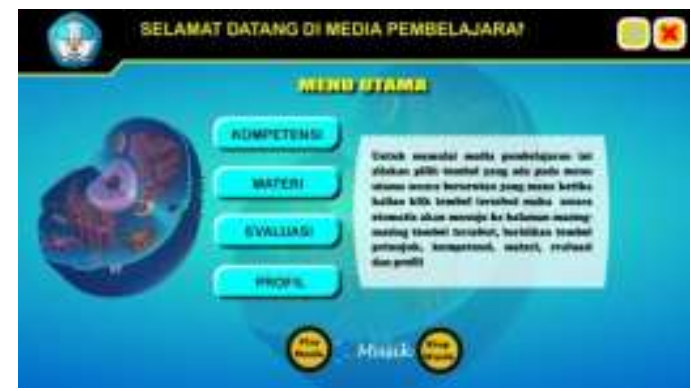

Gambar 1. Tampilan Utama

Gambar 1 merupakan halaman yang berisi tombol yang berfungsi untuk mempermudah pengguna dalam menjalankan atau mengakses tampilan yang diinginkan. Tombol-tombol yang berada di halaman utama tersebut antara lain Kompetensi, Materi, Evaluasi, dan Profil.

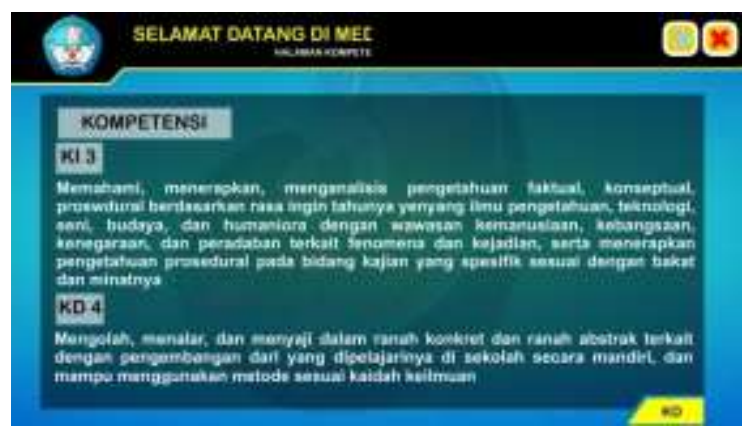

Gambar 2. Tampilan Kompetensi

Gambar 2 Halaman kompetensi berisi informasi mengenai Kompetensi Inti, kompetensi dasar yang dibuat. Isi dari Kompetensi Inti dan Kompetensi Dasar dalam program ini disesuaikan dengan silabus pembelajaran biologi.

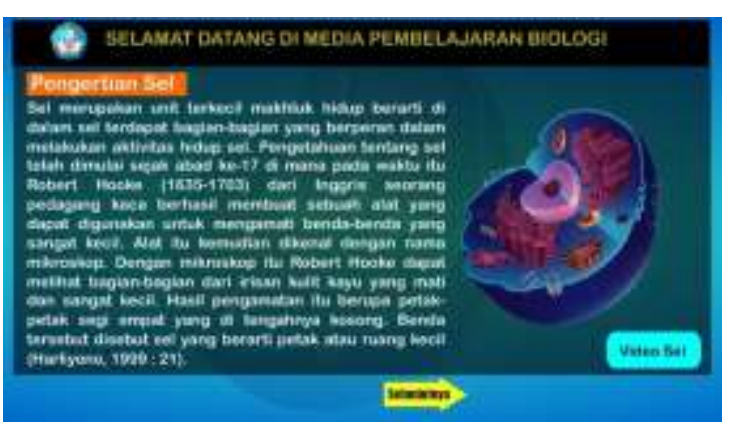

Gambar 3. Tampilan Menu Materi

Gambar 3 tampilan menu materi. Halaman materi ini merupakan sub menu dari halaman menu utama. Adapun dalam halaman materi ini terdapat menu untuk menghubungkan ke materi berupa teori. 


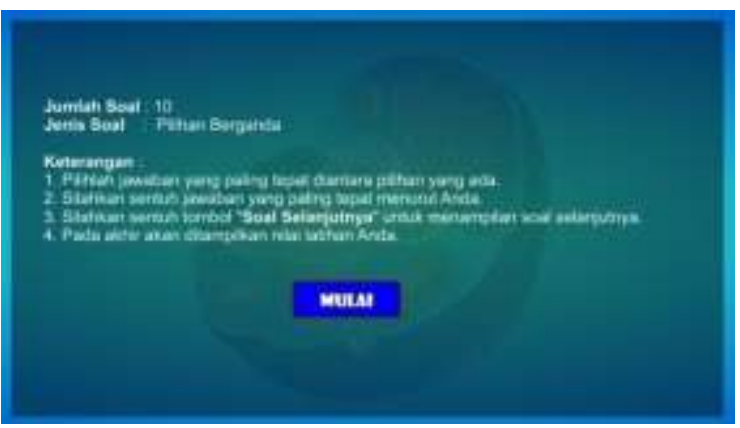

Gambar 4. Tampilan Evaluasi

Halaman evaluasi berisi soal-soal yang digunakan untuk mengukur kemampuan siswa. Soal pada media berupa pilihan ganda.

\section{Pembahasan}

Sesuai dengan tahapan yang sudah dilakukan dalam pembuatan media pembelajaran berupa media pembelajaran berbasis android, dikatakan bahwa media pembelajaran ini dikembangan sesuai dengan kurikulum mata pelajaran biologi kelas XI.

Media pembelajaran berbasis android ini telah melalui tahapan evaluasi pramaster yang diawali dengan para ahli. Untuk validasi atau penilaian yang dilakukan kepada ahli desain adalah sebagai berikut:

Tabel 1. Hasil penilaian oleh ahli desain

\begin{tabular}{|c|c|}
\hline Indikator & Nilai \\
\hline Ke-1 & 76 \\
\hline Ke-2 & 80 \\
\hline Ke-3 & 78 \\
\hline Ke-4 & 76 \\
\hline Ke-5 & 79 \\
\hline Ke-6 & 78 \\
\hline Ke-7 & 77 \\
\hline Ke-8 & 77 \\
\hline Кe-9 & 80 \\
\hline Ke-10 & 79 \\
\hline Total Nilai Jawaban & 780 \\
\hline Jumlah Indikator Pertanyaan & 10 \\
\hline Rata-Rata & 78,0 \\
\hline
\end{tabular}

Berdasarkan tabel di atas, rata-rata hasil penilaian ahli desain adalah 78. Berdasarkan tabel skala kelayakan, nilai 78 berada pada interval 75\% - 89\% dengan kategori "Baik".
Tabel 2. Hasil penilaian oleh ahli media

\begin{tabular}{|c|c|}
\hline Indikator & Nilai \\
\hline Ke-1 & 80 \\
\hline $\mathrm{Ke}-2$ & 76 \\
\hline Ke-3 & 79 \\
\hline $\mathrm{Ke}-4$ & 80 \\
\hline Ke-5 & 79 \\
\hline Ke-6 & 75 \\
\hline Ke-7 & 75 \\
\hline $\mathrm{Ke}-8$ & 75 \\
\hline Ke-9 & 80 \\
\hline Ke-10 & 80 \\
\hline Ke-11 & 80 \\
\hline Ke-12 & 79 \\
\hline Ke-13 & 80 \\
\hline Total Nilai Jawaban & 1018 \\
\hline Jumlah Indikator Pertanyaan & 13 \\
\hline Rata-Rata & 78,30 \\
\hline
\end{tabular}

Berdasarkan tabel di atas, rata-rata hasil penilaian ahli media adalah 78,30. Berdasarkan tabel skala kelayakan, nilai 78,30 berada pada interval 75\% - 89\% dengan kategori "Baik".

Tabel 3. Hasil penilaian oleh ahli materi

\begin{tabular}{|c|c|}
\hline Indikator & Nilai \\
\hline Ke-1 & 80 \\
\hline Ke-2 & 80 \\
\hline $\mathrm{Ke}-3$ & 83 \\
\hline Ke-4 & 83 \\
\hline Ke-5 & 78 \\
\hline Ke-6 & 80 \\
\hline Ke-7 & 78 \\
\hline $\mathrm{Ke}-8$ & 82 \\
\hline Ke-9 & 78 \\
\hline Ke-10 & 78 \\
\hline Ke-11 & 80 \\
\hline Total Nilai Jawaban & 880 \\
\hline Jumlah Indikator Pertanyaan & 11 \\
\hline Rata-Rata & 80 \\
\hline
\end{tabular}

Berdasarkan tabel di atas, rata-rata hasil penilaian ahli materi adalah 80. Berdasarkan tabel skala kelayakan, nilai 80 berada pada interval 75\% - 89\% dengan kategori "Baik". 
Tabel 4. Hasil penilaian skala perorang (3 orang siswa)

\begin{tabular}{|c|c|}
\hline Indikator & Nilai \\
\hline Ke-1 & 241 \\
\hline Ke-2 & 243 \\
\hline Ke-3 & 243 \\
\hline Ke-4 & 234 \\
\hline Ke-5 & 245 \\
\hline Ke-6 & 244 \\
\hline Ke-7 & 235 \\
\hline Ke-8 & 240 \\
\hline Ke-9 & 235 \\
\hline Total Nilai Jawaban & 2160 \\
\hline Jumlah Indikator Pertanyaan & 9 \\
\hline Rata-Rata & 80 \\
\hline
\end{tabular}

Berdasarkan tabel di atas, rata-rata hasil penilaian skala perorang adalah 80 . Berdasarkan tabel skala persentase, nilai 80 berada pada interval $80 \%-100 \%$ dengan kategori "Baik Sekali".

Tabel 5. Hasil penilaian skala kecil (8 orang siswa)

\begin{tabular}{|c|c|}
\hline Indikator & Nilai \\
\hline Ke-1 & 241 \\
\hline $\mathrm{Ke}-2$ & 243 \\
\hline Ke-3 & 245 \\
\hline Ke-4 & 234 \\
\hline Ke-5 & 245 \\
\hline Ke-6 & 244 \\
\hline Ke-7 & 242 \\
\hline Ke-8 & 240 \\
\hline Ke-9 & 235 \\
\hline Ke-10 & 240 \\
\hline Ke-11 & 238 \\
\hline Ke-12 & 240 \\
\hline Ke-13 & 235 \\
\hline Total Nilai Jawaban & 3122 \\
\hline Jumlah Indikator Pertanyaan & 13 \\
\hline Rata-Rata & 80,05 \\
\hline
\end{tabular}

Berdasarkan tabel di atas, rata-rata hasil penilaian skala kecil adalah 80,05. Berdasarkan tabel skala persentase, nilai 80,05 berada pada interval $80 \%$ - 100\% dengan kategori "Baik Sekali".
Tabel 6. Hasil penilaian skala lapangan (26 orang siswa)

\begin{tabular}{|c|c|}
\hline Indikator & Nilai \\
\hline Ke-1 & 241 \\
\hline Ke-2 & 243 \\
\hline Ke-3 & 245 \\
\hline Ke-4 & 238 \\
\hline Ke-5 & 245 \\
\hline Ke-6 & 244 \\
\hline Ke-7 & 242 \\
\hline $\mathrm{Ke}-8$ & 240 \\
\hline Ke-9 & 235 \\
\hline Ke-10 & 245 \\
\hline Ke-11 & 238 \\
\hline Ke-12 & 240 \\
\hline Ke-13 & 245 \\
\hline Total Nilai Jawaban & 3141 \\
\hline Jumlah Indikator Pertanyaan & 13 \\
\hline Rata-Rata & 80,5 \\
\hline
\end{tabular}

Berdasarkan tabel di atas, rata-rata hasil penilaian skala perorang adalah 80,5. Berdasarkan tabel skala persentase, nilai 80,5 berada pada interval 80\% - 100\% dengan kategori "Baik Sekali".

\section{Kesimpulan dan Saran}

Berdasarkan hasil penelitian dan pembahasan tentang pengembangan media pembelajaran berbasis android yaitu melalui beberapa tahap yaitu tahap uji coba ahli dan tahap uji coba ke lapangan. Hasil evaluasi pramester yang dilakukan oleh ahli media diperoleh 78,30 dengan predikat baik, evaluasi ahli desain diperoleh persentase 78 dengan predikat baik, dan ahli materi menilai produk yang dibuat dengan persentase 80 predikat baik. Jadi keseluruhan nilai rata-rata persentase pada validasi ahli memperoleh kriteria kelayakan Baik.

Setelah dilakukan uji kelayakan para ahli maka dilanjutkan dengan uji coba perorangan diperoleh rata-rata persentase 80 dengan predikat baik sekali, uji coba skala kecil diperoleh rata-rata persentase 80,05 dengan predikat baik sekali, dan uji coba skala besar diperoleh rata-rata persentase 80,5 dengan predikat baik sekali. Jadi secara keseluruhan nilai rata-rata persentase pada responden memperoleh kriteria kelayakan Baik Sekali. 
Berdasarkan hasil dari beberapa tahap uji coba yang dilakukan oleh ahli dan responden dapat disimpulkan bahwa media pembelajaran berbasis android ini layak diterapkan dalam pembelajaran Biologi di kelas XI.

Berdasarkan hasil penelitian yang telah dilakukan, peneliti memberikan saran pada peneliti berikutnya, yaitu agar dapat mengembangkan dan membenahi penyusunan program pembelajaran pembelajaran berbasis android dengan bentuk soal yang lebih kompleks agar menghasilkan program yang lebih baik. Menambahkan animasi-animasi agar media pembelajaran tampak lebih menarik.

\section{Referensi}

[1] Slameto. (2010). Belajar dan Faktor-Faktor yang Mempengaruhinya. Jakarta: PT. Rineka Cipta.

[2] Kuswanto, Joko \& Radiansah, Ferri, "Pengembangan Media Pembelajaran Berbasis Android Pada Mata Pelajaran Sistem Operasi Jaringan Kelas XI," Media Infotama, Vol. 14, No. 1, 2018.

[3] Kuswanto, Joko "Perancangan Media Pembelajaran Model Game Mata Pelajaran Penjaskes Kelas V," SITECH, Vol. 2, No. 1, 2019.
[4] Umar, "Media Pendidikan," Tarbawiyah. Vol 10 (No 2), 2013.

[5] Suryani, Nunuk \& Agung, Leo. 2012. "Strategi Belajar Mengajar." Yogyakarta: Ombak (Anggota IKAPI)

[6] N. Safaat. 2015. “Android: Pemrograman Aplikasi Mobile Smartphone dan Tablet PC Berbasis Android." Bandung: Informatika.

[7] Sari, Dian Kartika. 2018. “Pengembangan Aplikasi Android Mobile Dictionary And Emulatorperintah Dasar Command Line Interfacelinux dan Windows". Skripsi tidak diterbitkan. Yogyakarta: Program Studi Pendidikan Teknik Informatika Universitas Negeri Yogyakarta.

[8] Kuswanto, Joko, "Pengembangan Modul Interaktif Pada Mata Pelajaran IPA Terpadu Kelas VIII," Media Infotama, Vol. 15, No. 2, 2019.

[9] Putra, Nusa. 2011. "Research E Development Penelitian dan Pengembangan: Suatu Pengantar." Jakarta: Rajawali Pers.

[10] Warsita, Bambang, 2008. "Teknologi Pembelajaran Landasan dan Aplikasinya." Jakarta: Rineka Cipta. 